\title{
Approaches to Pain Management: A Review
}

\author{
Modupe Iretiola Builders* \\ Department of Pharmacology and Toxicology, Bingham University, Karu, Nigeria
}

*Corresponding author: Modupe Iretiola Builders, Department of Pharmacology and Toxicology, Faculty of Pharmaceutical Sciences, Bingham University, Karu, Nigeria

\begin{abstract}
Pain mismanagement is associated with low recovery, high morbidity, increase hospital stay, decrease patient satisfaction, high costs of admission and adverse drug reactions due to inappropriate analgesic prescriptions. Therefore, optimal pain management is of utmost importance in promoting recovery and improving quality of life. This review describes the pharmacological and nonpharmacological approaches to the management of pain.
\end{abstract}

Keywords: Pain; Pharmacological; Non-Pharmacological; Management; Analgesics

\section{Introduction}

Pain is an unpleasant emotional situation which causes reduction in living quality and functional situation of the patients linked with increase in the fatigue levels resulting in impairments of daily life activities in working capacity and social interactions [1]. There are two types of pains: nociceptive and neuropathic pain. Nociceptive and neuropathic pains can either be acute or chronic; however, neuropathic pains are the major contributors to most chronic pains. Nociceptive pains arise from damaged tissues and wounds such as compound fracture, burns, bruises, and inflammatory disorders are typically nociceptive [2].

\section{Pharmacological approach to the management of pain}

The management of pain requires the management of the whole patient, rather than the irrational prescription of analgesic resulting to abuse of this important class of drugs without providing adequate relief of pain. The prescription of analgesic is governed by the severity of pain, the individual needs and the circumstances of the patient [3]. Pain killers (Analgesics) currently represent the mainstay of pain management, with an array of drugs available, aspirin, acetaminophen, non-steroidal anti-inflammatory drugs (NSAIDs), mixed agonist and antagonists and narcotic analgesics [4].

\section{Non-pharmacological approach to pain management}

Pain is the commonest symptom that takes patients to doctors, but the complaint does not mean that an analgesic is needed. Although drug therapy is the mainstay of pain treatment, it is not all pains that are needed to be relieved by drugs [5]. Simple measures can be used to control some types of pain. [1]. The nonpharmacological therapy of pain management is considered to help the standard pharmacological treatment in pain management. This management aims to treat the affective, cognitive, behavioral and socio-cultural dimensions of the pain. Non-pharmacological methods can be used to control some types of pain and they are invasive methods and non-invasive methods [4].

\section{Conclusion}

Optimal pain management is the right of all patients and the responsibility of all health professionals, therefore health professionals managing individuals with pain must understand the anatomy and pathophysiology of the various conditions affecting the human body as well as the mechanism and pharmacology to support the various treatment strategies. Health professionals must combine both pharmacologic and non-pharmacological methods for effective management of pain and provision of comfortable and productive life. 


\section{References}

1. Builders MI, Bassi AM (2017) Evaluation of analgesic usage in pain management in Bingham University Teaching Hospital. Science Journal of Clinical Medicine 6(5):86-90.

2. Builders PF, Builders MI (2016) Wound Care: Traditional African Medicine Approach. Chapter contributed to the book topics on Worldwide Wound Healing. Innovation in natural and conventional methods 1:120-126.
3. Builders MI, Okonta JM, Aguwa CN (2011) Prescription patterns of analgesics in a community hospital in Nsukka. Journal of Pharmaceutical Sciences and Research 3:1593-1598.

4. Builders MI, Bassi PU (2017) Assessment of analgesic usage among the patients in Bingham University Teaching Hospital. International Journal of Medicine and Biomedical Research 6(2):92-100.

5. Demir Y (2012) Non-Pharmacological Therapies in Pain Management, Pain Management. In: Gabor Racz (Edt.), Current Issues and Opinions, ISBN: 978-953-307-813-7.

\section{(c) (?) This work is licensed under Creative}

To Submit Your Article Click Here:

Submit Article

DOI: $10.32474 /$ LOJPCR.2020.02.000132

Lupine Online Journal of
Pharmacology \& Clinical Research
Assets of Publishing with us
Global archiving of articles
- Immediate, unrestricted online access
Pharmacology \& Jlinical Research

